\title{
Reconstructing Crustal Thickness Evolution from Eu Anomalies in Detrital Zircons
}

\author{
Ming TANG ${ }^{1,2}$, WeIQIANG Ji ${ }^{3}, \mathrm{Xu} \mathrm{CHU}^{4}, \mathrm{ANBIN} \mathrm{WU}^{5}$, \\ CHEN CHEN ${ }^{2,6}$
}

${ }^{1}$ School of Earth and Space Sciences, Peking University, Beijing 100871, China. Email: mingtang@pku.edu.cn

${ }^{2}$ Department of Earth, Environmental and Planetary Sciences, Rice University, Houston, TX 77005, USA

${ }^{3}$ State Key Laboratory of Lithospheric Evolution, Institute of Geology and Geophysics, Chinese Academy of Sciences, P.O. Box 9825, Beijing 100029, China

${ }^{4}$ Department of Earth Sciences, University of Toronto, 22 Russell Street, Toronto, Ontario M5S 3B1, Canada

${ }^{5}$ College of Geoscience, China University of Petroleum, Beijing, China

${ }^{6}$ CAS Key Laboratory of Mineralogy and Metallogeny, Guangzhou Institute of Geochemistry, Chinese Academy of Sciences, Guangzhou 510640, China

Here we calibrate a crustal thickness proxy based on $\mathrm{Eu}$ anomalies in zircons. We show that, in felsic rocks, zircon $\mathrm{Eu} / \mathrm{Eu}^{*}$ (chondrite normalized $\mathrm{Eu} / \mathrm{sqrt}(\mathrm{Sm} * \mathrm{Gd})$ ) correlates with whole-rock $\mathrm{La} / \mathrm{Yb}$, which in turn can be used to infer crustal thickness. The resultant positive correlation between zircon $\mathrm{Eu} / \mathrm{Eu}^{*}$ and crustal thickness can be explained by two processes happening at high pressure: (1) depression of plagioclase and (2) endogenic oxidation of $\mathrm{Eu}^{2+}$ due to garnet fractionation. The $\mathrm{Eu} / \mathrm{Eu}^{*}$-in-zircon proxy for crustal thickness makes it possible to reconstruct crustal thickness evolution in magmatic arcs/orogens using detrital zircons. We then applied our Eu/Eu*-in-zircon crustal thickness proxy to southern Tibet. We measured the detrital zircons separated from modern river sands in the Gangdese belt, southern Tibet. Our results reveal a major crustal thickening trend since the Eocene, and possibly an earlier thickening process in the late Cretaceous. These findings are consistent with field observations of contractional deformations of sedimentary strata in southern Tibet. 